\title{
GCU
}

Glasgow Caledonian

University

University for the Common Good

\section{Establishing an evidence base for adapting social housing for an ageing population} Boyle, Frank; Thomson, Craig

Published in:

Journal of Financial Management of Property and Construction

DOI:

10.1108/JFMPC-06-2015-0021

Publication date:

2016

Document Version

Author accepted manuscript

Link to publication in ResearchOnline

Citation for published version (Harvard):

Boyle, F \& Thomson, C 2016, 'Establishing an evidence base for adapting social housing for an ageing population', Journal of Financial Management of Property and Construction, vol. 21, no. 2, pp. $137-159$. https://doi.org/10.1108/JFMPC-06-2015-0021

\section{General rights}

Copyright and moral rights for the publications made accessible in the public portal are retained by the authors and/or other copyright owners and it is a condition of accessing publications that users recognise and abide by the legal requirements associated with these rights.

Take down policy

If you believe that this document breaches copyright please view our takedown policy at https://edshare.gcu.ac.uk/id/eprint/5179 for details of how to contact us. 


\section{Establishing an evidence base for adapting social housing for an ageing population}

\section{Frank Boyle}

Frank Boyle, Project Manager and Business Improvement Co-ordinator, Irvine Housing Association, Irvine, North Ayrshire, UK.

Since 2005, Frank has been a Project Manager and Business Improvement Co-ordinator with Irvine Housing Association with experience of managing projects ranging from $£ 350 \mathrm{~K}$ office refurbishments to $£ 6.5 \mathrm{~m}$ new build housing schemes. He worked for 0.5 year secondment (2011-13) as a Research and Performance Co-ordinator with North Ayrshire Council coordinating and managing the research and development project for the Housing Strategy for Older People. He also spent one year (2013-14) working as an Industrial Project Coordinator with PCL Construction working in Canada in the Oil and Gas Sector. He is currently undertaking a part time PhD at Glasgow Caledonian University.

\section{Dr Craig Thomson (Corresponding author)-}

Dr Craig Thomson, Lecturer in Sustainability and the Built Environment, Department of Construction and Surveying, School of Engineering and Built Environment, Glasgow Caledonian University, Glasgow, UK.

craig.thomson@gcu.ac.uk

Craig has been a Lecturer in Sustainability and the Built Environment at Glasgow Caledonian University since 2011 having joined as a Research Fellow in 2006. He holds an undergraduate Geography degree, and spent 5 years with the Construction Management Research Unit (CMRU) at the University of Dundee where he completed both an MRes and a PhD. He has strong research interests in sustainability assessment; sustainability as a driver for innovation; and in the promotion of learning amongst practitioners about sustainability; in addition to expertise in the areas of project management, construction innovation, and knowledge management. He is currently Programme Leader for BSc Environmental Management. 
Purpose- Prolonged life expectancy coupled with the retirement of the "post war baby boomers" has resulted in an exponential rise in the $50+$ population, peaking in the UK in 2035. Recognising that longevity is often not accompanied by health, mobility or quality of life; the 'Shifting the Balance of Care' agenda promotes an integrated care model based around the resident's home. The research explores the adaptability of the existing social housing stock and how it relates to the requirements and preferences of the ageing population.

Design/methodology/approach- This research focuses at the local authority level, with the lead author embedded within North Ayrshire Council to establish the evidence base for their Housing Strategy for Older People. Following a constructivist grounded theory approach, key themes emerge through consultation with a working group, wider stakeholder groups and an iterative review of policy and literature. These themes were explored through an evidence base of available health and housing datasets, and a questionnaire survey of 1,500+ people aged 50+ exploring housing preferences and needs for older people; six focus groups split between residents and social housing providers and stakeholder interviews.

Findings- The scale and acute nature of the problem facing social housing providers is highlighted and reveals an alarming information gap within housing datasets exposing an inbalance between the supply and demand, and in realising the cost implications for adapting the housing stock.

Practical and social implications- It is important to resolve this information gap to develop the social housing stock, respond to preferences and establish solutions appropriate for its residents.

Originality/value- This work strengthens calls for a cohesive and integrated housing, health and social care system and exposes the challenge of delivering this at a local authority level. Keywords: ageing population, social housing, shifting balance of care, adaptation Article classification: Research or Case Study 


\section{Introduction}

Emerging as a key consideration in national planning is an exponential rise in the 50+ population over the next 20 years with slow recognition that the implications extend beyond traditional concerns related to pensions and health care. The population projections show that the percentage of those aged $60-74$ will increase by $79 \%$ and the numbers aged +75 is expected to rise by $55 \%$ by 2035 (GROS, 2010). In Scotland focus is turning to its implications on housing with the National Older People's Housing Strategy (Scottish Government, 2011) representing an attempt to plan for the implications of this scenario. The Strategy attaches significant focus on ensuring that the housing stock is suitable and calls on providers to consider the options available to match the needs of a rapid rise in the older population, especially those with a poor quality of mobility and long term conditions (Clough et al., 2003). When coupled with decreasing budgets and reduced new build rates, this demographic shift creates a unique set of circumstances requiring to be met by making best use of the existing housing stock and managing resources across all tenures and sectors (Croucher and Wilcox, 2009, Lansley et al., 2004b). Social housing providers face a heightened challenge as they experience a higher portion of the problem given the strong correlation between their tenants and higher instances of poor health and quality of life in old age often a number of years earlier than those in other housing sectors (Tunstall et al., 2013). When placed in the context of decreased funding for new build solutions, social housing providers face an acute problem which restricts their choices outside of the existing housing stock and places strain on already constrained budgets (Taylor-Goodby, 2012).

This research presents an empirical study which explores the scale of the demographic problem at a local level, establishing key themes and an evidence base for the future development of social housing within the North Ayrshire Council (NAC) area. Local Authorities play a key role in setting the context and managing the integration of service delivery although there is no one size fits all approach due to the variations of each area through geography, social-economic factors and the nature of the stock (NIC, 2005). Following a constructivist grounded theory (GT) approach the key themes emerged through iterative consultation with stakeholders, a review of the policy context and contemporary debates. These were then explored through a large scale questionnaire survey of residents, selected interviews and six focus groups with service providers and residents. In tandem, secondary sources are considered to review evidence related to demographic and housing management databases. This research represents the first time the $50+$ population have been specifically considered within the datasets or consulted about their housing needs and preferences for the long term (2012 to 2035) with NAC requiring a methodological approach to be established.

\section{Housing an ageing population}


In the UK, $90 \%$ of older people live in general needs housing, with only 5 to $6 \%$ living in specialist housing with support, $3.5 \%$ in care homes and $0.3 \%$ in long term hospital care (Pannell and Blood, 2014; Wilcox and Perry, 2014). The level of specialist housing with support is significantly lower than other comparable nations, a fact highlighted in the House of Lords report in 2013 on "Ready for Aging" (House of Lords, 2013). The social housing sector is increasingly housing a widening range of people in specialist housing including $1 / 3$ of new applicants below pensionable age, responding to increasing homelessness, a rise of registered disabilities and an increased number of $85+$ moving from private ownership (Pannell et al., 2012). Indeed Pannell and Blood (2012) suggest that a reduction of onsite staffing, and residents with a diversity of ages and housing needs is having an impact on the cohesion and therefore quality of life of residents in specialist social housing. When compared to specialist housing within the owner-occupied and private rented sectors these concerns are not shared. Developers seeking to build sheltered and specialist older people communities blamed budget and planning restrictions, lack of land availability, a preference for mixed developments and resistance for low density housing for limiting the prioritisation and expansion of specialist housing (both sheltered and residential care) across all sectors (Hurst, 2014; Spur, 2014). As a consequence, the focus has increasingly turned to the adaption of general needs housing and the challenge in the short to medium term of its need to meet the complex requirements of these changing demographics (Priemus, 2014; Hamza and Gilroy, 2011).

\section{Shifting the Balance of Care to the home}

The "Shift in the Balance of Care" agenda (SBC) (Scottish Government, 2009) has seen a renewed focus towards managing health and social care for older people within their own homes as opposed to investing in the provision of new housing specifically for older people such as sheltered/ specialist housing or care homes (Richards et al., 2006). The complexity of delivering this agenda through a housing focused strategy requires a range of service providers to engage and work together on a multitude of complex and dynamic factors. Christie (2011) argued that this will be impossible without an integrated approach which places housing firmly in the collective provision of health and social care. The local authority is viewed as the strategic body for delivering this agenda as they act as housing managers establishing housing planning policy, permitting development opportunities, managing social housing provision and in working closely with other Social Housing Providers (i.e. Registered Social Landlords). Significantly they also are a lead partner in the delivery of health and social care working with stakeholders such as the NHS and other providers. This culminates in a unique set of individual and collective agendas with each local authority reflecting different demographic patterns requiring an emphasis to be placed on local solutions.

With limited new build solutions development plans require to focus on the adaptation and long term maintenance of their existing stock responding to the preferences and needs of 
the ageing population (Best and Porteus, 2012). Local authorities require an evidence base to be presented for a wider Strategy for Older People to guide the delivery of integrated housing, health and social care (Christie, 2011). Early attempts for services to work together have revealed an apparent information gap which is hampering sufficient understanding of the scale of the problem at a local authority level and therefore the ability to plan and assess cost implications (HAPPI, 2009). Relating the predicted care needs and the preferences of older residents with the condition and suitability of the housing stock is necessary for social housing providers to effectively manage their stock availability, condition and potential for adaption (Croucher, 2008).

\section{Responding to the housing needs of older people}

Ensuring that the housing stock meets the needs of an older person is highlighted by its link with determining their quality of life, and surveys of older people indicate that overwhelmingly they want to remain independent and in their own homes as long as possible (Vasara, 2015; Richards et al., 2006; Evans, 2003; Appleton, 2003). The adaption of general needs housing to reflect the changing needs of residents is argued to be important in promoting independence within the homes they often brought up their family (HAPPI, 2009, Goodacre et al., 2007). Housing managers have historically focused on reactive adaptations responding to the resident's actual needs through a needs assessment then to relate this to their housing choices. However, SBC has promoted a need to focus on adaptations which not only respond or react but instead increasingly predict future care needs, often beyond what is demanded or even desired by the resident themselves (highlighted even by a recommendation for re-housing). Concern exists that with the rise in costs for long term care at an individual level, a growing trend is observed with owner occupiers selling and applying to social housing sector due to financial pressures following retirement with a recent survey finding $42 \%$ of retired renters (social and private sector) were former owner occupiers (Pannell and Blood, 2014). This has seen a growth in coownership developments, but with limited new build solutions, it remains the general needs housing which remaining the focus (Hope et al., 2012; Ball, 2012).

Evidence suggests that a small investment in adaptation or equipment has been linked to sizable reductions in formal care spending on hospitals, care homes and subsidies for shelter housing environments (Christie, 2011; Audit Commission, 2010). Recognition of the potential savings which can be achieved is essential if housing is to play a key role in delivering health and social policy and enable a shift from the costly residential and hospital care of older people which forms part of the current unsustainable care model (COSLA, 2011; Lansley et al., 2004b). Current practice requires an evaluation of wider housing options to assess if adaptation is appropriate given the resident's needs, size or nature of the property (housing options are classified as: Mainstream Housing, Specialist Housing or Residential Care Homes (HAPPI, 2009)). With extensive new build housing not a viable option and increasing demand for social housing; finance and planning is required to ensure 
the general housing stock can be suitable and ready to meet the needs but also the expectations of its residents preferably in the same neighbourhood.

A key requirement is to resolve the current information gap surrounding the supply and demand for their housing stock enabling an evaluation of the potential for adaption, the suitability and cost implications for the long term and future care needs of the residents. This is not available within current census and housing management data sets and without this it is difficult to accurately assess the implications for future budgets. This will have significant financial implications for local authorities, housing associations and other social housing providers, and will be heavily dependent on specific local factors such as the demographics, geography, levels of deprivation, age and type of the housing stock.

\section{Building and asset management}

Despite strong lobbying from the construction industry for a new build specialist housing solution to stimulate market growth, this is unlikely in the short to medium term.

Professional bodies such as CIOB, RICS and ICE have called on the industry to embrace the current opportunities by focusing on the existing stock and to ensure it poses the knowledge, skills and capacity to deliver the adaption and maintenance in short and long term (Byles, 2013). Working with social housing providers is increasingly important in order to understand and revise their planned and reactive work programmes to accommodate changing resident requirements and to adapt the stock to integrate resources between health, social care, and housing provision and management (Lansley et al., 2005). A long term view is necessary with adaptability needing to be the focus through the design, construction, handover and the long term maintenance of the stock highlighted by Lifetime Home Standards, as well as principles of whole life value and the wider sustainability agenda (Kelly et al., 2014; Ellingham and Fawcett, 2012; Harding, 2008). Social housing, health and social care providers need to work together with the construction industry to ensure the capacity and skills are provided to support the adaptation of the housing stock as well as ensuring its long term asset management (Best and Porteus, 2012). Social landlords are asking developers and construction professionals to help them to reduce costs and work with them in the adaptation and maintenance of the general needs housing stock. However, the information gap relating to the suitability of the existing housing stock (supply) and the preferences and needs of an ageing population (demand) can be argued to make it impossible from a practical perspective to effectively shape development and service plans requiring a baseline in order to establish an integrated care approach. This research seeks to develop a methodology which can help close the information gap at a local level and facilitate stakeholder dialogue during the development of OPHS.

\section{Research strategy and methods}

\section{A practice based research problem}


Adopting the local authority as the unit of analysis acknowledges the level where most of the decisions related to the delivery of housing, health and social care services are made and seeks to reflect and respond to the needs of the context of that area (demographics, health and deprivation levels, condition of housing stock and physical geography). Concern over the demographic challenges faced by an ageing population is well established in the literature for over two decades, but a gap remains for new insights at a local level relating to its implications on service delivery from the perspective of those delivering it. The research provides empirical understanding of the data requirements providing a pragmatic methodological approach which other councils could adopt in the future.

The authors undertook discussions with various local authorities in Scotland, and NAC responded strongly and created a funded post for the first author to be embedded within the authority and to provide the evidence base for their new Older People Housing Strategy (OPHS). NAC were one of the earliest authorities in Scotland to develop an OPHS. Following the completion of their Local Housing Strategy 2011-2016 North Ayrshire Council (NAC) identified an information gap relating to the suitability of their general needs housing stock to effectively respond to their demographic needs which is a pattern consistent across the UK. The council sought an exploratory study to establish the empirical data required to form an operational plan for developing the housing stock in line with the needs of the older population in the short, medium and long term forming the basis for the production for the OPHS. Working with the Housing Divisional Manager as a point of contact, the research sought to respond to the wants and needs of the older population, in addition to being able to justify any recommendations.

\section{Constructivist GT approach}

A constructivist GT approach represents an evolution of grounded theory rooted in pragmatism and relativism permitting theory and data to emerge through the interactions of the researchers with the field and its participants thus emphasising that it is through coconstruction that this is achieved (Mills et al., 2006). In this research it is not possible to retain an impartial position in the manner advocated by Glaser (1967) given the embedded position within the local authority. In addition, it was necessary to view the stakeholders as more than simply providing evidence but in line with their role in policy development they are viewed as participants in the evolution of the research. Stakeholder engagement helps shape the emerging themes and to consider implications for practice, and also plays a significant role in facilitating larger scale data collection. Charmaz's (2009) argues that constructivist GT enables the space for researchers to acknowledge their position and role in analysing data and the importance of working with participants (i.e. stakeholders) as part of the process.

The consideration of literature is important for this research, with Charmaz (2009) arguing that constructivist GT permits the researcher to explore the state of the art in a dynamic manner and allowing its influence in the evolution of the themes. This has been argued to 
form a middle ground between Glaser's (1967) realist tradition of limiting the influence of preconceived ideas in the emerging theory, or Straus and Corbin's (1992) post-modernist approach where literature is used to influence the development of the coding frameworks from an early stage but still from an objective position. In establishing an evidence base for the OPHS it is not possible to ignore the contemporary policy and debates relating to housing an ageing population. Constructivist GT permits the interrelationship and coconstruction of meaning between the researchers (reflecting their position), the participants and the literature (in this case the need to engage the policy agenda) in a pragmatic data sensitive way (Thornberg, 2012; Hayes and Oppenheim, 1997). The themes emerge through an iterative process allowing a coding structure to develop which is reflexive of the local context (based on stakeholder engagement and related to evidence).

Figure 1 shows the research process illustrating the significant level of consultation and engagement with key stakeholders in the early stages to help shape themes, questions and prompting iteration with the policy agenda and key debates within the literature. The initial stages aided the development of the methods and sample for later stages through a range of explorative primary and secondary methods. Themes were explored through a large scale questionnaire survey of $1,50050+$ residents across all tenures, six focus groups with stakeholders and interviews exploring housing needs and preferences, and analysis of existing data sets to consider evidence relating to the demographics of North Ayrshire, housing stock profile and cost of actual renovations within the social housing stock within the Council area.

\section{INSERT FIGURE 1}

Figure 1: Research process

\section{Establishing key themes and engagement}

The research started with a literature review to establish the initial themes related to this agenda from both the policy and research communities. In order to guide the overall process, a working group was formed comprising of senior members from relevant internal departments within NAC i.e. Housing Services, IT (GIS specialists), Social Care, and also from external bodies such as the NHS. A series of workshops were conducted to identify the key stakeholders for the research, explore the emerging themes from literature review and to establish the most appropriate methods of engagement.

The stakeholders were split into three categories-

Category 1: Older People (50+) living in four different housing sectors: Local Authority Rental sector, Registered Social Landlord sector, Owner Occupier, and Private Rental Sector. 
Category 2: related to service delivery partners external to local authority: Registered Social Landlords, Private Sector providers, Voluntary Sector \& Charities and the Joint Improvement Team (Scottish Government).

Category 3: represented service delivery partners (internal) such as Housing Services, Social Services, Health (NHS), Infrastructure and Design and Elected Members.

The list of stakeholders and key themes emerging were presented during several consultation events with each of the stakeholder categories to verify and further develop these for the local context. The process of stakeholder engagement aimed to ensure inclusion and transparency is assured during policy development reflecting a commitment to stakeholder management and satisfying a requirement for NAC (Simmons and Lovegrove, 2005).

The key themes established:

- The acute nature of the demographic problem facing social housing in NAC

- The growing transition to social housing from owner occupiers in retirement

- The shortage of social housing which meets the needs and preferences of older people

- Recognition of an information gap relating to the condition and cost of adapting general needs housing

- An emerging recognition of the cost of not adapting and investing in equipment

- The need for housing asset management to reflect training needs and lifetime adaptability

- Implications of an integrated care model

\section{Triangulation with available datasets}

The consultation events with key stakeholders provided the basis for the research strategy shaped around secondary and primary data sources. The working group revealed an understanding of current data sets, areas which lack detail and the existence of data gaps. This was confirmed through the consideration of the existing data sources which are managed internally within NAC or by partner service providers relevant to the geographical area. Standard secondary sources related to demographics (GROS census and population projections), North Ayrshire's relation to the Scottish Index of Multiple Deprivation (employment, health, education, housing, access, and crime), existing housing stock data (held in the North Ayrshire Housing Register (NAHR)) and future development plans represented in Sub-Market Housing Area's (SMHA). The NAHR provides information on all properties in NAC representing more detail than is currently held by RSL landlords. The first author as a development manager for the largest housing association in the area and was able to supplement this with access to tenure and housing management data and was involved in their future development planning. Data was also accessed relating to cost of adaptation of general needs housing within NAC and through analysis reveals what 
information is available for an accurate understanding of the demand and condition of the existing housing stock providing a starting point to assess the cost implications for adopting the general needs social housing.

The current housing demands outlined in the current NAC Local Housing Strategy (LHS) and Local Development Plan (LDP) are taken from the Housing Needs and Demand Assessment (HNADA) and this lacks information on age specific housing demand making it difficult to plan effectively a future strategy. The research sets out to provide triangulation between different data sets and to explore this in the context of the needs and preferences of older people. The HNAHR includes all social housing applications and enables insight into the demand for older people specific accommodation and other housing preferences of those aged $50+$ looking for a social rented property and this is explored.

\section{Resident's questionnaire survey}

A questionnaire survey was deployed to evaluate wants and needs of older people in relation to housing preferences at a local level (across all tenures). The research intended to use a probability sample to determine the minimum sample size in line with other survey's deployed by NAC accessible through council tax data, however it was quickly apparent that this does not include age specific details. The use of a non-probability sampling method enabled the creation of quota categories and sample size in order to represent the population using GROS mid-year population estimates identifying the estimated 50+ population within North Ayrshire by tenure. In order to overcome boundary problems with census data zones and SMHA, Geographical Information System (GIS) software was crucial in determining the best geographical fit of data zones within SMHA's. Given the complexity of establishing the sample an experienced consultancy (Research Resource) were asked to recommend acceptable confidence intervals per SMHA and Settlement Area (an aggregation of data zones). A sample size of 1,522 from a total population of 52,822 (GROS 2011) was agreed as sufficient to reflect a $95 \%$ confidence level with $+/-7 \%$ per settlement across NAC area, and +/- $2 \%$ across NAC as a whole and to provide a robust general insight into the $50+$ population of North Ayrshire's housing preferences, across all tenures. Regardless of arguments around statistical laws for representing populations through samples, the consultants developed the most robust method that could be financially afforded given the available data and budget for its collection. The sample took a quota controlled approach based on 10 interviews linked to each sample point with 50+ resident's representative of tenure within that census data zone. This allowed for quotas to be developed through stratification by ward and 19 sampling points drawn in each ward. The questionnaire was developed using a range of closed and open questions responding to themes identified through the literature review and the earlier consultation events with stakeholders. The survey was conducted on the basis of an interview held at their home conducted following NAC protocols which align with social research guidelines and ethics deployed within the public sector. This was demonstrated in the use of 2 representatives from the council to 
minimise bias, quality control ensured through external review and ethics with respondents offered confidentiality and anonymity in the publication of findings.

Focus groups and sense checking interviews

Six focus groups were conducted to explore the central themes which emerged through the previous stages. The groups had differing focuses with four representing older residents in different parts of North Ayrshire exploring their perceptions and needs reflecting varying deprivation levels, and two with service providers in housing, health and social care exploring the implications and challenges faced. A set of sense checking interviews with key stakeholders from the working group were conducted to explore the findings and relate these to their practice based experience. The transcripts were developed and analysed using the evolving coding framework enabling the findings to be triangulated with the secondary data and iteratively considered against state of the art and policy agenda bolstering and adding weight to the emerging recommendations.

\section{Research analysis and findings}

The acute nature of the demographic problem facing social housing in NAC

Stakeholders started each of the consultation events by independently expressing a clear concern that North Ayrshire faced an acute demographic problem when compared to the national average. Analysis of key statistical indicators confirms this perception and that this problem is heightened by a predicted increase in demand for social housing for the $50+$ population beyond levels observed nationally. Part of this picture is caused by a higher instance of social housing tenure in those below $50+$ than in the current older population, a situation reflective of an increasing level of deprivation in North Ayrshire in this age range. This stakeholder observation is supported by Figure 2 which displays a projection of the age profile in 2035 from a base line of 2010 revealing a decline in NAC's overall population, but an increase exists between 65 and 74 with a further increase observed for the over 75's. Such a dynamic will see an increasing proportion of the overall population represented by those 50+ in higher levels than will be experienced nationally. The potential exists for a decline in the under 65 population to free up stock for over 65 's, but this research sets out to establish whether the current stock is both suitable for their needs or even desirable to their expectations, and this stakeholders felt remains a big question.

\section{INSERT FIGURE 2}

Figure 2: 20 Year Age Profile Projections for North Ayrshire

(Source: GROS, 2010)

Despite the high levels of deprivation, a significant geographical disparity in these levels across North Ayrshire emerged as a key concern in the consultation events and these patterns were confirmed using the Scottish Index of Multiple Deprivation showing contrast 
between affluent coastal towns like Largs and on the island of Arran, and inland towns with some of the highest levels of deprivation recorded in Scotland. The coastal towns currently have a high population of 65+ residents, representing a significant proportion of NA's owner occupiers and the popularity of these towns for retirement. A significant concentration of social housing is observed within the inland towns such as Irvine with nationally high levels observed across all age ranges. The coastal towns display high life expectancy, and health data reveals an ability to maintain an active quality of life (with minimal mobility and care requirements) well into their old age. This contrasted with the inland towns, with lower life expectancies but also lower quality of life observed in their older age with an increasing proportion of those requiring care provision in their 50's and 60's. Increased care requirements, coupled with an observed increase in demand for social housing amongst those aged 50-64 within these inland towns was argued by stakeholders to provide potential implications for housing and care provision over the next 20 years. The data reveals two very different life experiences for older people in NAC reflecting a higher level of inequality than national average with reliance on the social housing sector showing higher levels of deprivation, an increasing proportion of older people on the housing register, and a poorer quality of life in the inland towns.

\section{The growing transition to social housing from owner occupiers in retirement}

The implications of an increased reliance on social housing were explored further in the focus groups revealing a concern amongst social housing providers that this situation may change over time as existing home owners facing affordability issues and potential pension shortfalls sell their homes and apply for social rented accommodation. Indeed early data within NAC is indicating that this trend has begun and the focus groups revealed five common perceptions which have the potential to further increase the reliance on social housing: 1) lack of suitable older people specific housing in the private sector; 2) lack of suitable older people specific housing in the private sector, 3 ) affordability issues with owner occupation in later years, 4) the need to release home equity to generate much needed additional income, and 5) a perception that the social rented sector is the main provider of older people specific housing (Research Resource 2011). The perceptions coupled with the increasing levels of poverty and pressure for equity release in older age was argued by stakeholders to result in housing solutions being sought by individuals out with the private sector, and a perceived drive by many for social landlords to move older people into smaller housing through the Welfare Reform Act 2012.

\section{The shortage of social housing which meets the needs and preferences of older people}

The initial stakeholder consultation events revealed a concern that as increasing demand is placed on the social housing stock due to increased demand and demographic change, there was a growing gap with the supply of suitable housing within North Ayrshire. Confirmation of this concern can be seen through firstly consideration of a breakdown of the property types currently available within the social housing stock as shown in figure 3 . This provides 
a useful baseline to compare the findings from the resident's survey regarding their preferences and needs broken down by age bracket (50-64; 65-74; 75+).

\section{INSERT FIGURE 3}

Figure 3: Stock Breakdown for Core Partners of Social Housing

(Source: North Ayrshire Council, 2011b)

The resident's survey revealed that within the 50-64 range there is generally a good mix of house types that would be acceptable and that the supply was available. Within the 65-74 range a very distinct pattern emerges with three clear house types emerging as preferences in priority order: Bungalows, Ground Floor Tenement and Ground Floor Four in a Block (Research Resource, 2011). A basic building stock survey for NAC revealed that the properties currently available within the social housing sector that fit these broad categories only equates to approximately $26 \%$ of the stock available. When explored further during a focus group a warning emerged that there is no guarantee that all of these houses will be suitable. Statistics back this observation with only $13 \%$ of current social housing is specifically for older people, with the remaining $87 \%$ designated for 'General Needs' with $10 \%$ as amenity properties and 3\% sheltered homes (NAC, 2011a and 2011b). In 2011, within the NAC area there was 66,439 homes across all sectors of the housing stock and only 2,229 homes within this stock is available for older people. With the population increase in $55+$ and especially in the $75+$ category it is uncertain from this data whether this will be sufficient to house this population and its increasingly complex needs. Analysis revealed that with new build rates of less than $0.4 \%$ (between 2005-2011) a picture is presented through the focus groups where despite an obvious demand, the finance and opportunities are absent for a building programme, a picture consistent with the literature review. This will result in the needs of the ageing population requiring to be facilitated predominantly through the existing stock and due to NAC's disproportionately high focus on social housing with $27 \%$ of stock compared to national average of $22 \%$ (revealed from council tax data), the challenge for social housing providers is clear.

The survey and then explored further through the focus groups that residents want to stay in their current homes, with figure 4 showing $77 \%$ would not want to move regardless of their care needs. Indeed, $88 \%$ of those surveyed had no current plans and $6 \%$ indicating they will possibly move but not for 5 years. Focus groups revealed a strong feeling that the transition from their general needs accommodation was not related to their age, but instead to either their own or partners health deterioration with the majority only moving at a point of crisis when there was no other option for their housing. The attachment to one's home coupled with the increased time people spend in their homes during older age, presents a need to encourage older people to think about their current housing circumstances and whether it would fit their changing needs if their health or mobility deteriorated (aligns with Lansley et al., 2004a). The main reasons emerging for people 
currently to consider moving were analysed across the age groups with the top three: accessibility, maintenance and affordability. This preference was analysed in detail within each age band and the results shown in Figure 5. These reasons are important for those managing the stock to consider especially the shift towards maintenance strongly in the 75+ grouping. Significant problems were reported for those moving in terms of market flexibility and mobility due mainly to the economic climate and a lack of suitable social housing for their needs. The dominant preference was for bungalows (63\% choice for those considering moving) due to its perceived increase in space and accessibility, however social housing managers reported that this was equally challenging as these tend to have a higher private market value and are rarely available in the social sector. The focus groups outlined an increasing problem caused by a lack of understanding amongst residents of the options available in terms of the house types within the stock, and their implications for differing care needs. An illustration of this point is the preference of maisonettes for $33 \%$ of those wanting to move, and a lack of understanding of what this would entail with reduced mobility. A need was identified for social housing managers to better advise, and raise awareness amongst older people of the choices available.

\section{INSERT FIGURE 4}

Figure 4: Future Housing Aspirations

(Source: North Ayrshire Council, 2011d)

\section{INSERT FIGURE 5}

Figure 5: Main reasons for moving home 50+

(Source: North Ayrshire Council, 2011d)

Recognition of an information gap relating to the condition and cost of adapting general needs housing

If general needs housing is to emerge as the key environment to deliver health and social care as part of the SBC agenda, social housing managers will need to assess the extent to which the stock can be adapted and respond to people's changing health and mobility needs. Focus groups revealed a need for a $100 \%$ stock condition survey which goes beyond the basic stock profile, and to capture the properties that have been and have potential for adaption with current data sets acknowledged as not being able to show this.

The principle option for older people who have a declining quality of life but wish to remain as independent as possible within their own home is through 'equipment and adaptations'. This term is used to describe a whole range of options that can help transform a home from a burden to a safe and independent living space. Remaining at home provides greater independence and a feeling of security to people who suffer from a long term illness or disability. In practice housing managers interpret equipment and adaptations as ensuring 
the building fabric is energy efficient (and so reducing fuel poverty), but also in assisting in preventing falls in the home, helping carers and improving physical and mental health of older people. Figure 6 illustrates the most common equipment and adaptations provided by NAC during 2009/10 and the typology applied. This highlights that investment is focused heavily on bathing solutions, ramps and stair lifts with around $£ 1.4$ million in total for adaption spent across NAC during this period. This sounds high, but stakeholders during the focus groups when asked argued that this figure needs to be higher and better targeted as the cost effectiveness of investing in equipment and adaptations when compared to the costs of emergency hospital admissions and associated care costs is increasingly undisputed (Heywood and Turner 2002). Consultation with literature shows the emergence of tele(health)care and various types of monitoring equipment such as fall mats, personal alarms, heat detectors is increasing the sophistication of equipment and adaptations for those with complex health issues such as dementia and other long term conditions (Tinker and Lansley, 2005). Social housing managers when consulted reported that this will increase the cost on the budget for adaptation and equipment especially with the innovations in SMART homes increasingly linked to monitoring stations with $24 \mathrm{hr}$ response teams to provide care in emergency situations but also monitor heating and movement patterns for older people. This places significant cost onto traditional housing budgets, but if a holistic approach is provided for housing, social and health care then this cost requires multiple stakeholders called for this to be viewed differently as a complete package of care. This agenda has the potential to place the home and community at the heart of future care provision and the focus groups/ interviews both revealed this as a clear direction of travel which needs to be met at a national and local policy level although a lack of information was recognised to restriction this.

\section{INSERT FIGURE 6}

Figure 6: Most common adaptations and annual costs

(Source: adapted from North Ayrshire Council, 2011c)

It is difficult to assess current demand for equipment and adaptations across North Ayrshire as there are currently numerous systems that hold information across NAC and RSL partners. These systems record the number of people waiting for adaptations within the social rented sector and private tenures. The information currently available was reported by stakeholders to be disjointed and was unavailable for analysis although providers reported during the focus groups that they are looking to address this. Jones (2014) has called for an Accessible Housing Register to be established in order to facilitate this information gap, with a combined database of residents awaiting equipment and adaptations with focus groups suggesting these should allow greater analysis and insight. However, evidence emerged that this agenda is slow to be realised in practice with focus groups highlighting the need for accessibility criteria for existing social rented housing stock to consider the current state of the stock and for mechanisms with service partners to 
determine what was needed (potentially through an Accessible Housing Register). It was clear that prior to this research, stakeholders didn't have an accurate feel for the needs or perceptions of older people.

\section{An emerging recognition of the cost of not adapting and investing in equipment}

The questionnaire survey revealed that as many as $29 \%$ of people who reported they needed equipment and adaptations, currently have not received the work, with $34 \%$ in the social housing sector. The focus groups revealed a perception that a significant percentage of older people may not be aware of how to access the equipment and adaptations that could increase their independence and quality of life. This situation needs to be resolved in order to reduce the risk for older people's health and resultant increased cost for the NHS with those awaiting installation running risk of falls and the associated emergency hospital admissions. One focus group found a common view that the links between housing and health are not always immediately obvious; however there is no doubt that one affects the other (Davis et al., 2009). A good example of this link is the number of patients hospitalised after a fall in the home; a particular area of concern within North Ayrshire as it has the fifth highest rate in Scotland (shown in figure 7) a fact repeatedly made by stakeholders representing the NHS. There is now a substantial body of evidence that a high proportion of falls in the home could be avoided through increased resources and focus on preventative housing related support (Heywood et al., 2002) with Age UK (2014) arguing that this can be achieved in a cost effective way. A health care professional during a focus group drew attention to the example of a standard new house design which can achieve Lifetime Home Standard for approx. $£ 1,500$ and that this equates to the cost of less than 6 days in hospital. This prompted a discussion which highlighted research by Age UK which illustrates the average cost of a hip fracture to health and social care as $£ 12,300$, and 1 year residential care costs as sitting at $£ 26,000$. Lansley et al. (2004a) argue that adaptations and assistive technology can be linked to a recouping of initial investment through lower care costs and the average life expectancy of the user, and consultation revealed that stakeholders understand this association. The benefits of a simple grab rail for example was suggested as having significant benefits for reducing falls, with costs sitting at $£ 20$ to $£ 40$ and as a result Age UK argue strongly that prioritisation of budgets to prevention will have immense savings for tax payers and increase the quality of life for older people (Age UK, 2014).

\section{INSERT FIGURE 7}

Figure 7: Patients hospitalised after a fall in the home (65+) (3-year average 2007-2009) (Source: ScotPHO, 2010)

The implications of falls at home represent a significant annual cost and as such, is monitored as a Scottish Government KPI target and NHS Boards in their Local Delivery Plans 2012/13 calling for housing providers to increase their role in helping to reduce rates of attendance in $A \& E$, reduce emergency inpatient bed days for people aged $75+$ per 1,000 by 
at least $12 \%$ between 2009 and 2015. Focus groups and interviews revealed an acknowledgment of the potential for a joint preventative housing approach to aid the delivery of this agenda but that this will require housing managers to place equipment and adaptations within their refurbishment, renovation and maintenance planned works regimes. During a poll taken at a workshop, $60 \%$ of older people agreed that prevention should be a priority and that this needed to be better supported regardless of who or how it was paid for. A housing officer argued that current adaption grants for owner occupiers were averaged at $£ 6,800$ which includes widening doors, installing ramps and stair lifts, adaption of heating and lighting controls. Although, social housing residents will not pay directly for this, it is a useful estimate of cost. Age UK (2014) revealed that only $3 \%$ of the current stock complies with the Lifetime Homes standard with $23 \%$ of homes occupied by older people being described as non-decent. An increase in the options available for older residents was requested strongly by the focus groups and aligns with Age UK's (2014) recommendations for a mixed housing strategy.

The need for housing asset management to reflect training needs and lifetime adaptability

Low level support was identified during discussions as playing a significant role in improving the quality of life of older residents and reducing the risk of falls around their home.

Maintenance is identified as playing a key role to ensure the equipment is functional and in removing the risk from around the house (i.e. carpets, doors, stairs, bathrooms, kitchens). Maintenance teams were argued during focus groups to need to engage more with older residents in order to respond to their preferences. The provision of handy men and tradesman who are trained to listen to older people's concerns and periodic risk assessments for trips and falls was suggested as a path to provide low level support which has a big impact. This suggests calls for a new joint approach between housing, health and social care is recognised by stakeholders as part of the policy agenda, but social housing providers still lack an understanding of the implications for the future development of their housing stock. Focus groups identified a current lack of preparedness within the local construction industry in terms number of companies with the capacity, knowledge and skills to support its delivery. A need for training was identified for professionals working with older people, often within their homes.

A key concern throughout the research was the need to ensure that properties were both flexible and adaptable; however a key barrier was noted in the poor build quality across the stock and its link to driving up adaption costs (observations which align with Wilcox and Perry, 2014). A key concern for housing managers was inefficiency observed when equipment requires removal and the reinstatement of properties for residents with different needs. This aligns with the $\mathrm{CIH}$ (2014) who argue that too often expensive adapted homes needed to be reconfigured or equipment removed for the next tenant. Numerous stakeholders provided anecdotal evidence relating to the lack of consideration of the lifetime implications of adaptation and the installation of equipment, with bathrooms cited 
as a key area of concern where short term adaptations presenting high levels of cost to reinstate. This problem has the potential to increase due to the enforced downsizing of properties through the Welfare Reform Act 2012, which has the knock on consequence of enforcing the removal of expensive adaptations and equipment reflecting concern expressed by Davis et al. (2014). An example is provided by $\mathrm{CIH} \mathrm{(2014)} \mathrm{relating} \mathrm{to} \mathrm{this}$ where they cite savings of $£ 2.4$ million in $2009 / 10$ through a UK strategy for recycling equipment in local authority properties, however focus groups argued that delivery had further to go. Pawson et al. (2011) argued that savings through a better use of specialist resources has the potential to offset the set up costs for Accessible Housing Register in 5 years. It is possible to suggest that a need for a life cycle appraisal of adaptations and installation of equipment is required in order to ensure that the option selected is beneficial for the resident but also represents long term value for the property. However, focus groups strongly highlighted that such decisions are not a priority for housing managers or even those providing the funding.

Implications for an integrated care model

A need exists for a new economic model which intrinsically links housing with health and social care as without this it is difficult to make the case for housing budgets to increase in isolation at the expense of other services. The pressures on housing and especially social housing are becoming more acute with the ageing population and the consensus from the service providers involved in the focus groups and interviews was that only a holistic funding and delivery model between the housing, health and social care can deliver this and provide best value and efficiency savings. The SBC agenda recognises this, but concern existed that there had not yet been the degree of change required in practice. The survey broached the subject and sought to gauge local opinion and priorities of the local residents on the future funding issues. The figures collated revealed that $55 \%$ thought that funding should come from general taxation, $27 \%$ believed it should be paid through a mixture of taxation and personal contribution and $8 \%$ wanted to see a public insurance scheme that everyone paid into to pay for care. The remaining $10 \%$ stated a variety of other options. Regardless of how care is paid for in the future it is important that older people's views are at the heart of process and any adaptation (Mackintosh, 2012) and the survey provides the first local insight into that debate.

\section{Conclusions and recommendations}

Adapting the social housing stock to reflect the needs of an ageing population will require financial resources to facilitate its delivery. This research revealed that an evidence base is required at a local authority level in order to effectively plan and budget for the current and future implications of a demographic change. A understanding of the scale of the shortfall in suitable stock and the nature of the demand reflecting local demographic needs and resident preferences is identified as limited amongst key providers of housing, health and social care. The other key finding was the importance of this evidence base to help establish 
the link between not adapting the general needs stock and the implications on older people from unsuitable housing and instances of fuel poverty, frequency of falls and the resultant cost implications for health and social care. Recognising the savings which can be made between the different services is the only way to establish a joint approach, and housing provides the key context within which this will be delivered. The SBC agenda has far reaching implications for social housing providers as they will experience a significant portion of the burden. This research argues that future planning is hampered by the observed information gap which stops an accurate picture emerging on the current condition of the stock and its ability to respond to the needs and requirements of the ageing population. The compilation of this data in a format that can be analysed and proven to be robust will be crucial in identifying the proportion of the housing stock capable of being used or adapted for older people. Findings highlighted that allowing social housing providers the opportunity to plan for the future requires a balance of existing housing currently and potentially available for housing older people across each Sub-Market Housing Area.

North Ayrshire provided a worked case study revealing that the current stock profile displays insufficient detail to determine what properties are suitable for older people and which properties have been and could be adapted. Data matching, cleansing of the software systems and collection of the data gaps is required in terms of stock condition with a view to considering demographic projections over the next 20 years. NAC has responded to this finding and is in the process of finalising a $100 \%$ stock condition survey which records a number of age specific criteria (e.g. accessibility of downstairs bathrooms) in order to construct a clearer picture of the housing stock. NAC are also constructing an accessibility criteria for the existing social rented housing stock to establish 'what they have' in order to identify 'what they need' both now and in the future, to house an ageing population. Private rented and owner occupier sectors were also identified as requiring further research given the emerging realisation that even less information was currently available relating to the stock condition and tenure amongst these sectors.

Having revealed the extent of the information gap a need is presented to establish a community profile (housing, health, and age profile relating to the $50+$ population) initially at SMHA level would help establish the needs of different areas, identifying hot spots for action based on pressures observed within the profile and to foster a business case for adapting suitable general needs housing for older people reflecting variations in care needs and preferences. These profiles have the potential to help justify and shape local authority decisions ensuring that the limited resources available are allocated effectively. The collation of robust data sets that are updated on a regular basis could provide a framework, identify data gaps and make best use of available information, with a view to making best use of the existing social housing stock. The findings have implications for social housing providers by highlighting the need to establish the readiness of the current stock by shaping future development plans for new build programmes, planned works (refurbishment) and 
reactive maintenance management. Work is then required with the construction industry to ensure knowledge, skills, and the capacity exists to deliver this in practice. Without this evidence, it is difficult to see how housing managers can plan the requirements to align their stock with the Shifting Balance of Care agenda, as well as the wider sustainability agenda (environmental, social and economic). NAC used the findings of this research as the basis for their OPHS (North Ayrshire Council, 2013) which sets out to create a multi-agency framework for joint delivery, however policy makers culture to experience a challenge in implementing the fullness of the recommendations due to the distance still required to effectively integrate the provision of housing with health and social care especially with a view to adapting the existing financial model.

\section{Acknowledgements}

The research would have never taken place if it was not for the foresight, resources and support given to me by North Ayrshire Council, the Housing Divisional Manager, and the Head of Community Care and Housing, the team at Research Resource, members of the working group, and the older people of North Ayrshire for participation in survey, focus groups and events.

\section{References}

AgeUK (2014), Housing in Later Life, Age UK, London.

Appleton, N. (2002), Planning for the Majority: The needs and aspirations of older people in general housing, Joseph Rowntree Foundation, York.

Audit Commission (2010), Tackling the Financial Challenge for Councils of an Ageing Population, Audit Commission, HM Government.

Ball, M. (2011), Housing Markets and Independence in Old Age: expanding the opportunity, Henley Business School, University of Reading, Reading.

Best, R. and Porteus, J. (2012), Housing our Ageing Population: plan for implementation, HAPPI2, All party parliamentary group on housing and care for older people, available at:

http://www.housinglin.org.uk/_library/Resources/Housing/Support_materials/Other _reports_and_guidance/Housing_our_Ageing_Population_Plan_for_Implementation .pdf (last accessed 15 June 2015).

Byles, T. (2013), “Housing for older people: an age-old problem”, Building Magazine, available at: http://www.building.co.uk/housing-for-older-people-an-age-oldproblem/5064350.article (accessed 15 June 2015).

Clough, R., Leamy, M., Bright, L., Miller, V. and Brooks, L. (2003), Homing in on housing: a study of housing decisions of people aged over 60, Eskrigge Social Research, Lancaster. 
Charmaz, K. (2009), "Shifting the grounds: Constructivist grounded theory methods", in Morse, J.M., Stern, P.N., Corbin, J., Bowers, B., Charmaz, K.and Clarke A.E. (eds.), Developing Grounded Theory: The Second Generation, Walnut Creek: Left Coast Press., pp. 127-154.

Chartered Institute of Housing (ClH) (2009), Housing, Health and Care, available at:http://www.dhcarenetworks.org.uk/_library/Resources/Housing/Support_materi als/Reports/Housing_Health_and_Care.pdf (accessed 15 June 2015).

Christie, C. (2011), "Report on the Future Delivery of Public Services", The Christie Commission, Scottish Government, available at: http://www.scotland.gov.uk/Publications/2011/06/27154527/0 (accessed 15 June 2015).

$\mathrm{CIH}$ (2014), How to make effective use of adapted properties, Chartered Institute of Housing, London.

COSLA (2011), "Reshaping Care for older People: A Programme for Change 2011-2021", available at: http://www.jitscotland.org.uk/action-areas/reshaping-care-for-olderpeople/ (accessed 15 June 2015).

Croucher, K. (2008), Housing Choices and Aspirations of Older People: Research from the New Horizons Programme, Department of Communities and Local Government, HM Government.

Croucher, K., Wilcox, S. (2009), An Examination of the Housing Needs and Supply for an Ageing Society, RICS Research, London.

Davis, S., Porteus, J. and Skidmore, C. (2009), "Housing, Health and Care, A policy and practice", report by Chartered Institute of Housing (CIH), Coventry.

Ellingham, I. and Fawcett, W. (2012) Whole Life Sustainability, RIBA Publishing, Newcastle upon Tyne.

Evans, G. W. (2003), "The built environment and mental health", Journal of Urban Health, Vol. 80, No. 4, pp. 536-555.

Goodacre, K., McCreadie, C., Flanagan, S., Lansley, P. (2007), "Enabling older people to stay at home: How adaptable are existing properties?", British Journal of Occupational Therapy, Vol. 70, No.1, pp. 5-15.

GROS (2010), Census and Population Projections for 2010, General Registers Office Scotland, Scottish Government.

Hamza, N., Gilroy, R. (2011), "The challenge to UK energy policy: an ageing population perspective on energy saving measures and consumption", Energy Policy, Vol. 39, No. 2, pp. 782-789.

Harding, E. (2008), "Sustainable planning for housing in an ageing population: a guide for regional-level strategies", International Longevity Centre UK, available at: http://www.ilc-alliance.org/images/uploads/publication-pdfs/pdf_pdf_49.pdf (accessed 15 June 2015).

Heywood, F. and Turner, L. (2002), Better Outcomes Lower Costs Summary, Department of Work and Pensions, HM Government. 
Hope, P., Bamford, S-M., Beales, S., Brett, K., Kneale, D., Macdonnell, M. and McKeon, A. (2012), "Creating sustainable health and care systems in ageing societies", The Global Health Policy Summit Report of the Ageing Societies Working Group 2012, available at:

http://www.improvingcare.co.uk/docs/Ageing_Societies\%20_Health_Report.pdf (accessed 15 June 2015).

House of Lords (2013), Ready for Ageing, Select Committee on Public Service and

Demographic Change Report of Session 2012-13, Stationary Office Limited, London.

Housing for Ageing Population Panel for Innovation- HAPPI (2009), Housing for Ageing Population Panel for Innovation Final Report, HAPPI- Home and Communities Agency, HM Government.

Hurst, W. (2013), UK 'failing' on housing for the elderly, Building Magazine, available at: http://www.building.co.uk/uk-failing-on-housing-for-the-elderly/5051917.article (accessed 15 June 2015).

Jones, C. (2014), "Adapting to the challenges of an ageing population for social housing", Housing LIN Viewpoint 57, available at:

http://www.housinglin.org.uk/_library/Resources/Housing/Support_materials/View points/HLIN_Viewpoint_57_Challenges.pdf (accessed 15 June 2015).

Kelly, J., Male, S., Graham, D. (2014), Value Management of Construction Projects, Wiley Blackwell, Chichester.

Lansley, P., Flannagan, R., Goodacre, K., Turner-Smith, A., and Cowan, D. (2005), “Assessing the adaptability of the existing homes of older people", Building and Environment, Vo. 40, No. 7, pp. 949-963.

Lansley, P., McCreadie, C., Tinker, A. (2004a), "Can adapting the homes of older people and providing assistive technology pay its way?", Age and Ageing, Vol. 33, No. 6, pp. 571576.

Lansley, P., McCreadie, C., Tinker, A., Flanagan, S., Goodacrea, K. \& Turner-Smith, A. (2004b), "Adapting the homes of older people: a case study of costs and savings", Building Research \& Information, Vol. 32, No. 6, pp. 468-483.

Mackintosh, S. (2012), From Home Adaptations to Accessible Homes: Putting people at the heart of redesigning the adaptation service in Bristol, Case Study No. 62, Housing LIN, London.

Mills, J., Bonner, A., and Francis, K. (2006), "The development of constructivist grounded theory", International Journal of Qualitative Methods, Vol. 5, No.1,available at:http://www.ualberta.ca/ iiqm/backissues/5_1/pdf/mills.pdf (accessed: 15 June 2015).

North Ayrshire Council (2013), "North Ayrshire's Older People Housing Strategy", North Ayrshire Council, available at: http://www.northayrshire.gov.uk/Documents/PropertyServices/HousingBuilding/older-peoplehousing-strategy.pdf (accessed: 15 June 2015).

North Ayrshire Council (2011a), "Council Tax Data Extract", (internal source).

North Ayrshire Council (2011b), "Housing Management Database", (internal source). 
North Ayrshire Council (2011c), "Adaptations Database”, (internal source).

North Ayrshire Council (2011d), "North Ayrshire Older People's Housing Survey (OPHS)" (internal source).

Office for the Deputy Prime Minister (ODPM) (2003), "Linking housing to health, social care and other strategies", available at:

http://icn.csip.org.uk/_library/Preparing_older_peoples_strategies.pdf (accessed 15 June 2015).

Pannell, J., Aldridge, H., Kenway, P. (2012), Market Assessment of Housing Options for Older People, New Policy Institute, London.

Pannell, J., and Blood, I. (2014), Quality and Choice for older peoples housing: what can a new private rented sector offer, Housing, Learning, and Improvement Network, PRS Briefing Paper 7, HLIN, London.

Pannell, J. and Blood, I. (2012), "Supported housing for older people in the UK: an evidence review", Joseph Rowntree Foundation, available at:

http://www.jrf.org.uk/sites/files/jrf/sheltered-retirement-housing-full.pdf (accessed 15 June 2015).

Pawson, H., Sosenko, F. and Atkins, J. (2011), "Evaluation of the London Accessible Housing Register". Heriot Watt University, available at:

http://www.hw.ac.uk/schools/energy-geoscience-infrastructure-

society/documents/Evaluation_of_the_LAHR_March_2011.pdf (accessed 15 June 2015).

Priemus, H. (2014), "Is the landlord levy a threat to the rented housing sector? The case of the Netherlands", International Journal of Housing Policy, Vol. 14, No. 1, 98-106.

Research Resource (2011), Older Peoples Housing Survey and Focus Group Report for North Ayrshire Council, Research Resource, Cambuslang.

Richards, F., Walker, G., Jarvis, L. (2006), Time to Move? A Literature Review of Housing for Older People, Scottish Executive Social Research, Scottish Executive.

Savilles (2011), "Reprogrammed 2012-2016 Decoding the next five years of the housing market", available at: http://pdf.euro.savills.co.uk/uk/residential-property-focusuk/residential-property-focus-q4-2011.pdf (accessed 15 June 2015).

ScotPHO (2010), "Health and Wellbeing Profiles 2010- North Ayrshire CHP", Scottish Public Health Observatory (ScotPHO), available at:

http://www.scotpho.org.uk/web/FILES/Profiles/2010/Rep_CHP_S03000002.pdf (accessed 15 June 2015).

Scottish Government (2012), Age, house and community: a strategy for home Scottish older people: 2012-2022, Building Environment and Housing, The Scottish Government.

Scottish Government (2011), National Older People's Housing Strategy, Built Environment and Housing, Scottish Government.

Scottish Government (2009), Shifting the Balance of Care, NHS and Scottish Government. 
Spurr, H. (2014), "Retirement home planning rules must change, Inside housing report", available at: http://m.insidehousing.co.uk/report-retirement-home-planning-rulesmust-change/7006233.article (accessed 15 June 2015).

Simmons, J. and Lovegrove, I. (2005), "Bridging the conceptual: lessons from stakeholder analysis", Journal of Organisational Change and Management, Vol. 18, No. 5, pp. 495-513.

Taylor-Gooby, P. (2012), "Root and branch restructuring to achieve major cuts:the social policy programme of the 2010 UK Coalition Government", Social Policy \& Administration, Vol. 46, No. 1, pp. 61-82.

Terry, R. and Gibson, R. (2010), “Can equity release help older home-owners improve their quality of life?", Jospeh Rowntree Foundation, available at:

http://www.jrf.org.uk/publications/equity-release-older-home-owners (accessed 15 June 2015).

Thornberg, R. (2012), "Informed grounded theory", Scandinavian Journal of Educational Research, Vol. 56, No. 3, pp. 243-259.

Tinker, A., Lansley, P. (2005), "Introducing assistive technology into the existing homes of older people: feasibility, acceptability, costs and outcomes", Journal of Telemedicine and Telecare, Vol. 11 No. S1, pp. 1-3.

Tunstall, R., Bevan, M., Bradshaw, J., Croucher, K., Duffy, S., Hunter, C., Jones, A., Rugg, J., Wallace, A. and Wilcox, S. (2013) "The links between housing and poverty: an evidence review", Joseph Rowntree Foundation, April 2013, available at: http://www.jrf.org.uk/sites/files/jrf/poverty-housing-options-full.pdf (accessed 15 June 2015).

Vasara, P. (2015), "Not ageing in place: negotiating meaning of residency in age-related housing", Journal of Aging Studies, Vol. 35, pp. 55-64 (in press).

Wilcox, S. and Perry, J. (2014), "UK Housing Review 2014”, Chartered Institute of Housing $(\mathrm{ClH})$, available at:

http://www.cih.org/publication/display/vpathDCR/templatedata/cih/publication/da ta/UK_Housing_Review_2014 (accessed 15 June 2015). 


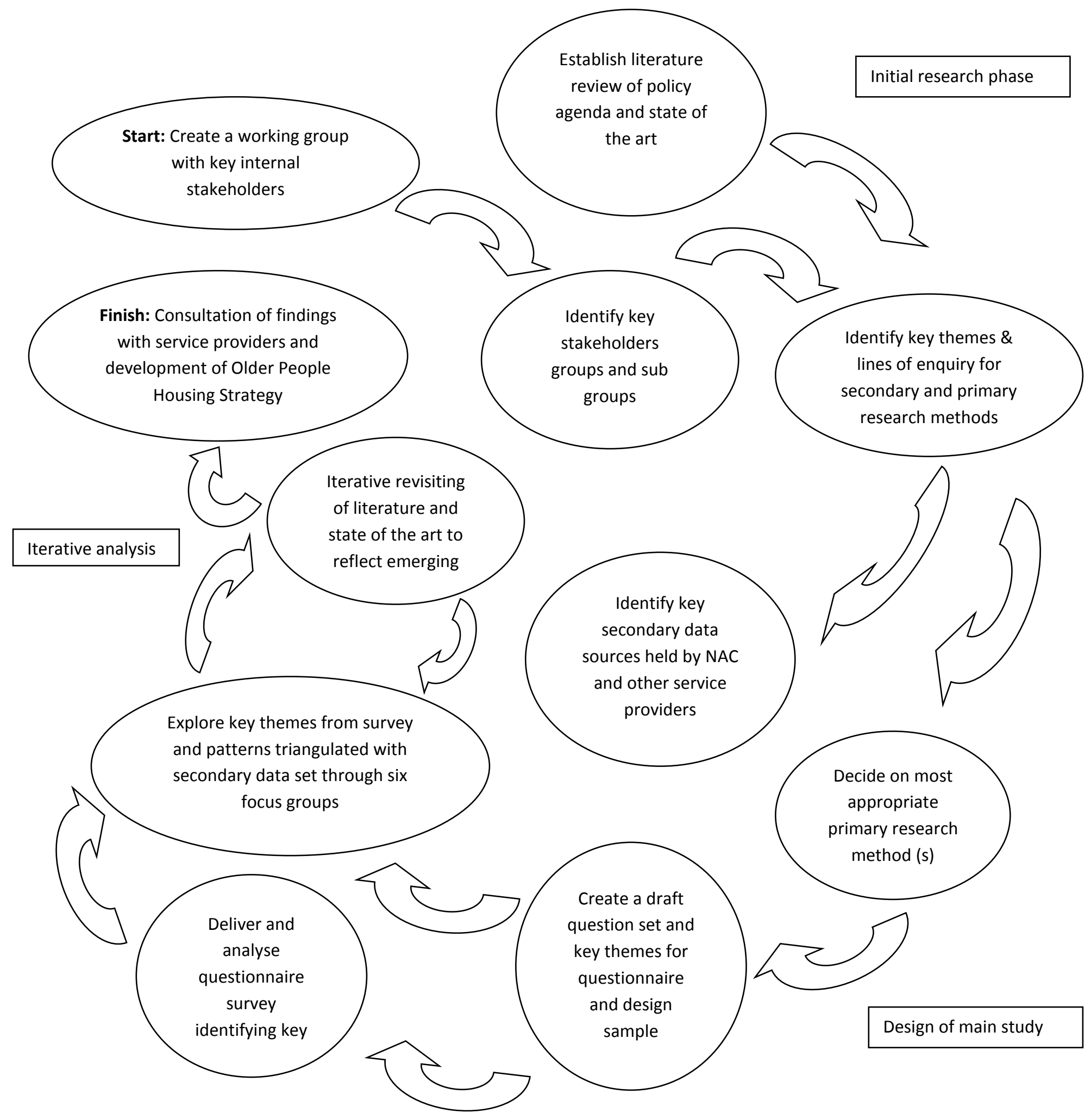

Figure 1: Research process 


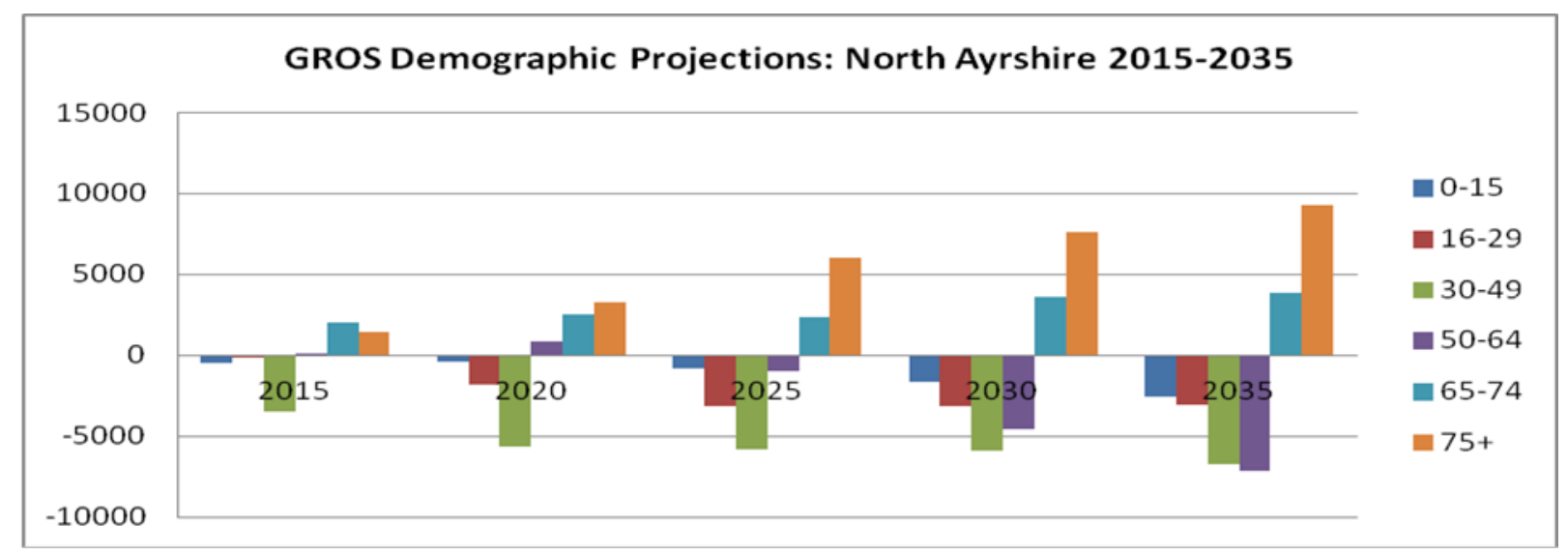

Figure 2: 20 Year Age Profile Projections for North Ayrshire (Source: GROS 2010)

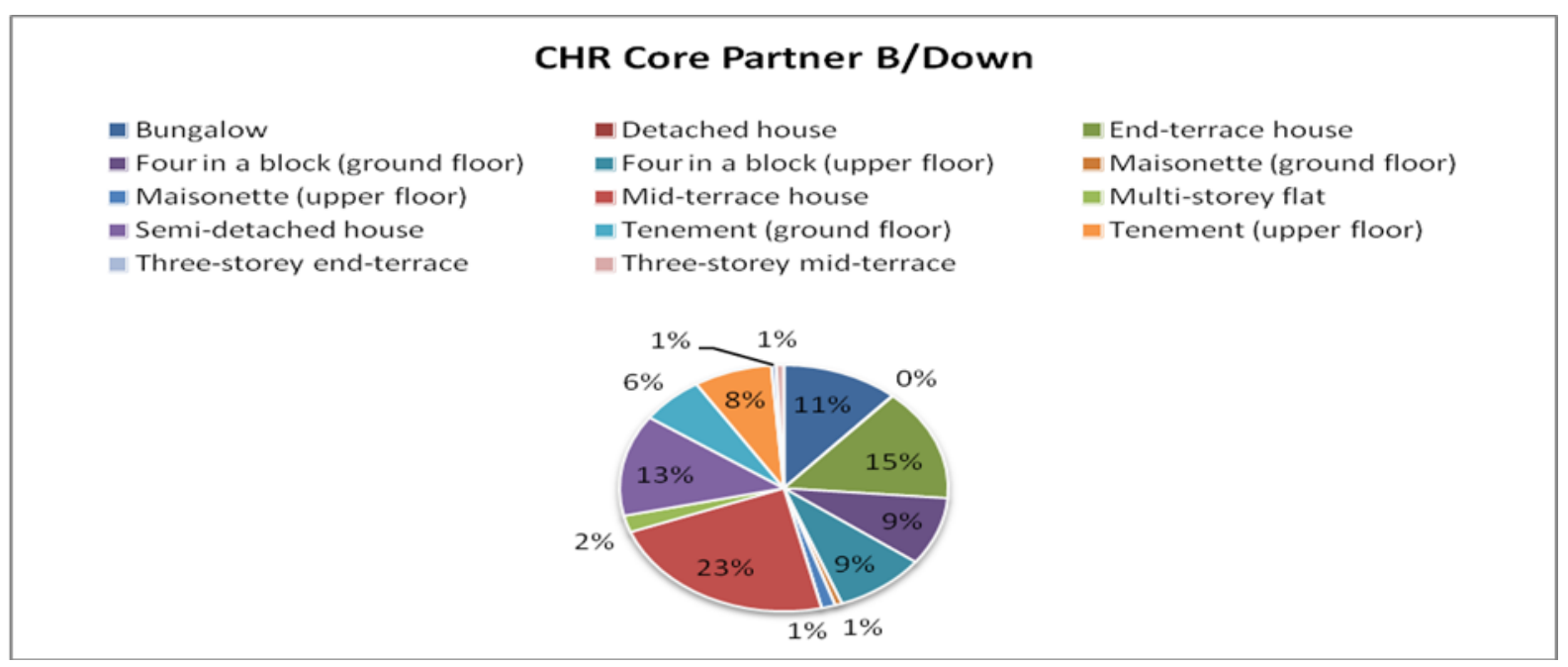

Figure 3: Stock Breakdown for Core Partners of Social Housing (Source: North Ayrshire Council 2011b) 


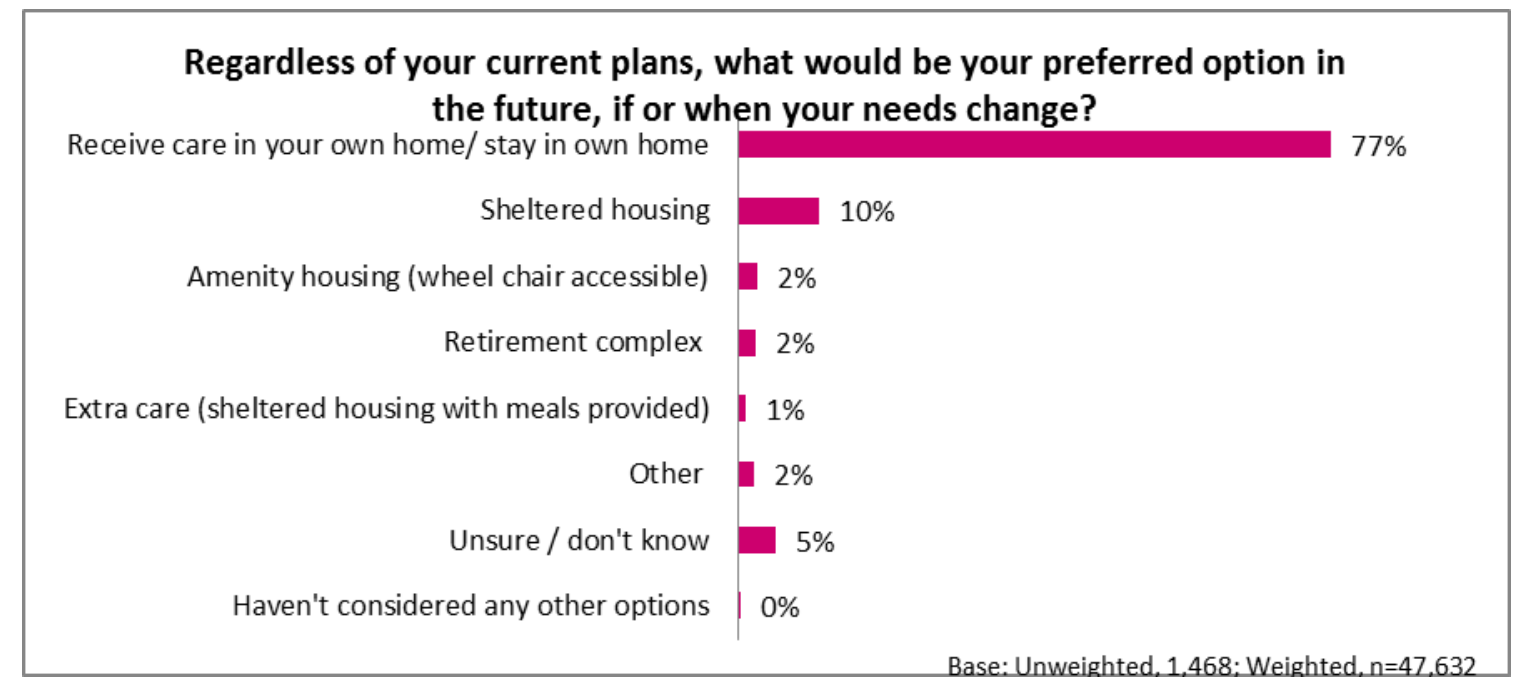

Figure 4: Future Housing Aspirations (Source: North Ayrshire Council, 2011d)

What are the main reasons for considering moving?

\begin{tabular}{|c|c|c|c|c|c|}
\hline Age band & Overall & $50-59$ & $60-64$ & $65-74$ & $75+$ \\
\hline Un-weighted & 173 & 56 & 31 & 65 & 21 \\
\hline \begin{tabular}{|l}
$\begin{array}{l}\text { Accessibility of property related } \\
\text { issues }\end{array}$ \\
\end{tabular} & $68 \%$ & $63 \%$ & $56 \%$ & $82 \%$ & $73 \%$ \\
\hline $\begin{array}{l}\text { Maintenance of property related } \\
\text { issues }\end{array}$ & $\mathrm{d}$ & $34 \%$ & $40 \%$ & $46 \%$ & $61 \%$ \\
\hline Affordability related issues & $47 \%$ & $49 \%$ & $49 \%$ & $44 \%$ & $40 \%$ \\
\hline $\begin{array}{l}\text { Desire to be closer to care/ support } \\
\text { network }\end{array}$ & $\mathbf{t} 12 \%$ & $18 \%$ & $7 \%$ & $9 \%$ & $4 \%$ \\
\hline $\begin{array}{l}\text { Area related issues e.g. facilities/ } \\
\text { crime }\end{array}$ & $11 \%$ & $11 \%$ & $11 \%$ & $11 \%$ & $11 \%$ \\
\hline Health related issues & $11 \%$ & $4 \%$ & $14 \%$ & $19 \%$ & $12 \%$ \\
\hline
\end{tabular}

Figure 5: Main reasons for moving home 50+ (Source: North Ayrshire Council, 2011d)

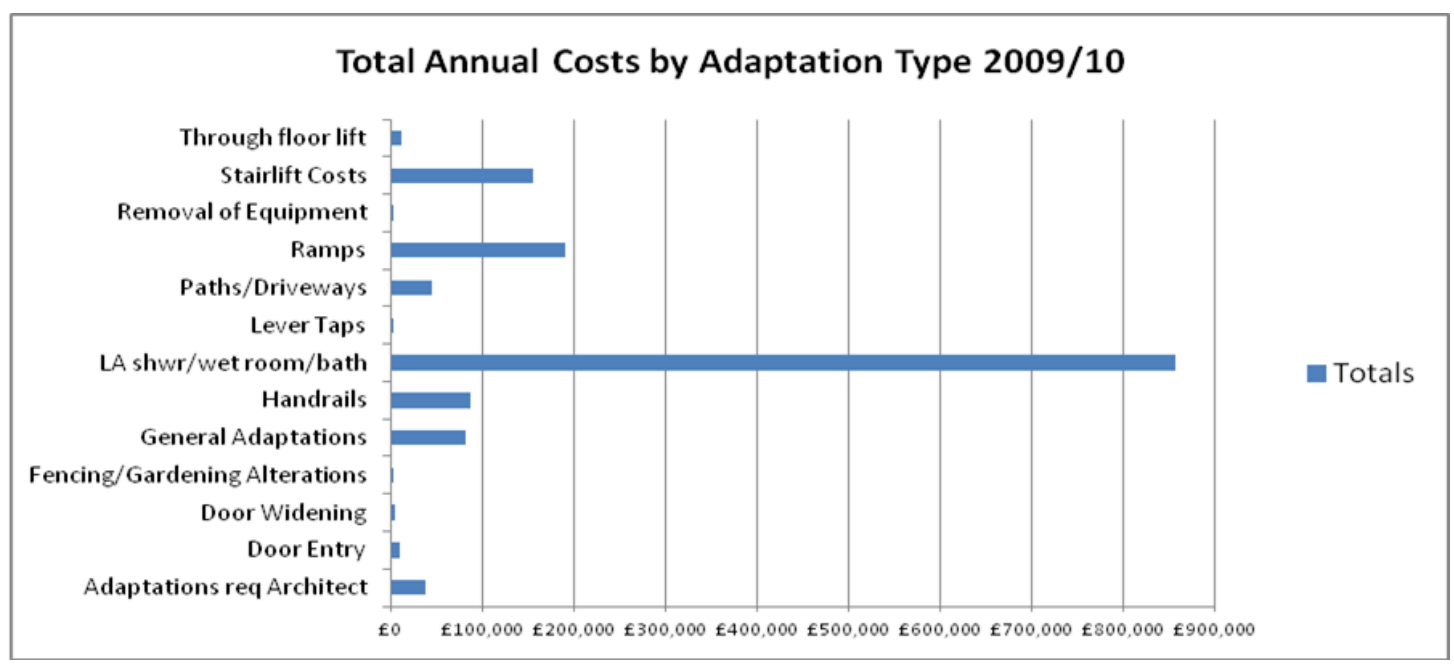

Figure 6: Most common adaptations and annual costs

(Source: adapted from North Ayrshire Council, 2011c) 


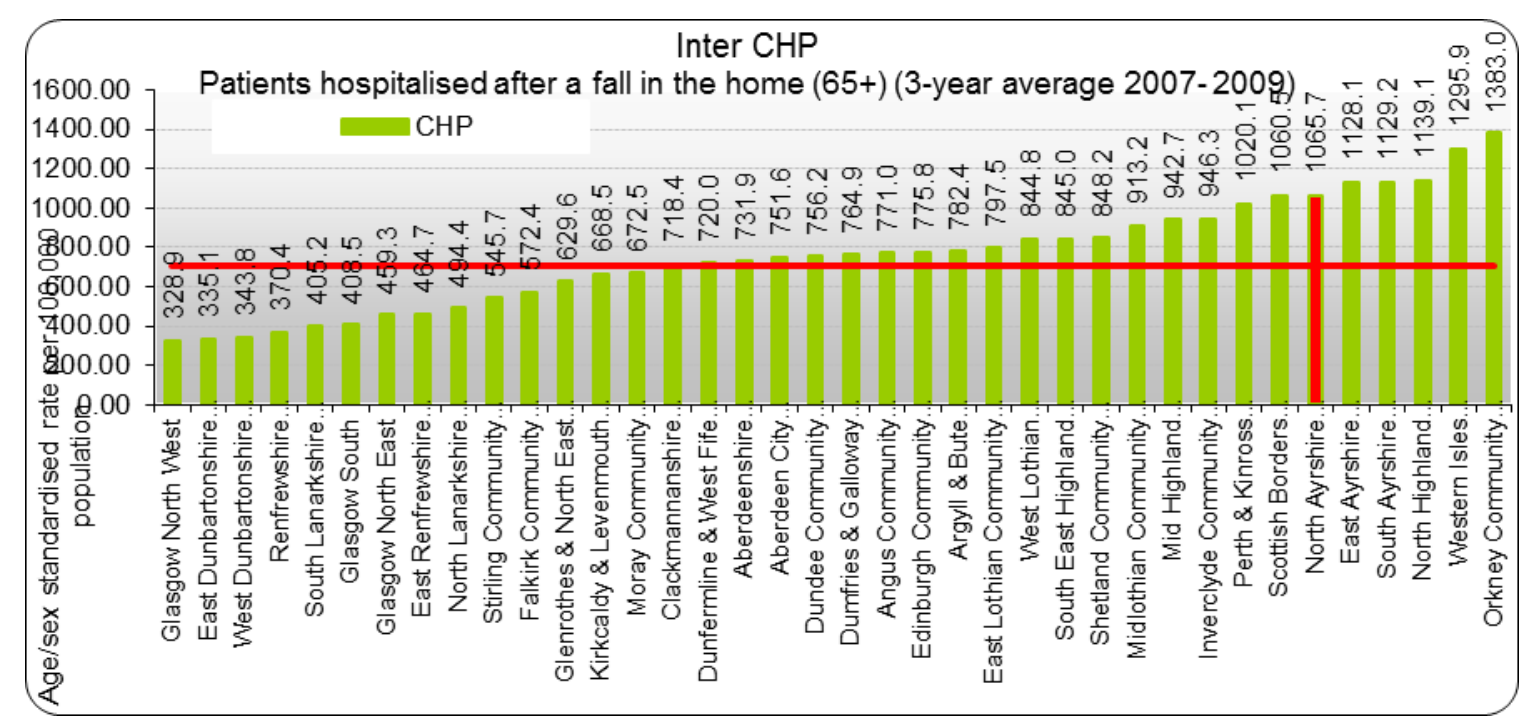

Figure 7: Patients hospitalised after a fall in the home (65+) (3-year average 2007-2009) (Source: ScotPHO, 2010) 